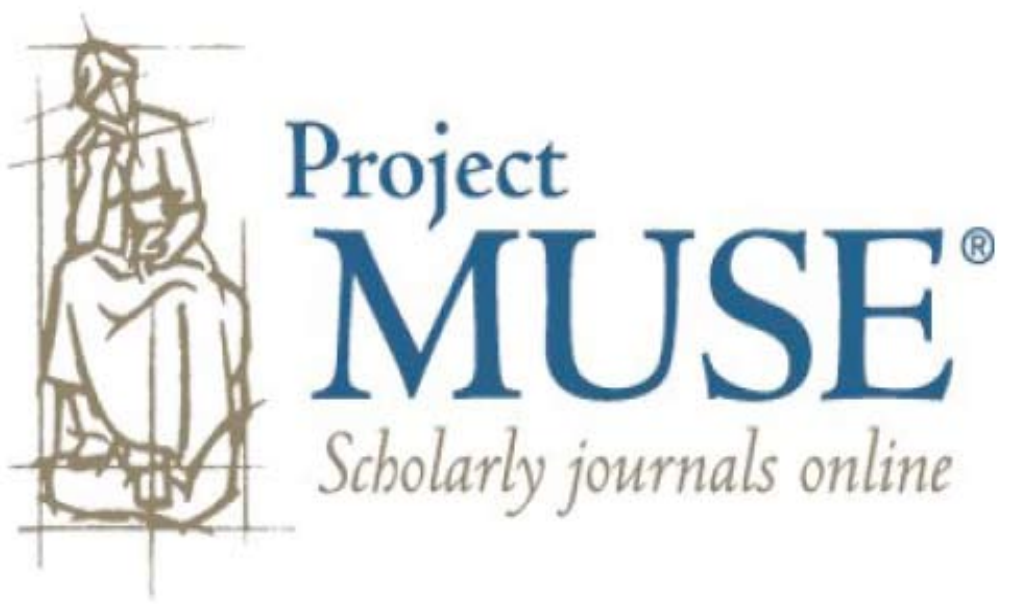




\title{
The Difference Between Science and Philosophy: the Spinoza-Boyle Controversy Revisited
}

\author{
SiMON DUfFY
}

\begin{abstract}
This article examines the seventeenth-century debate between the Dutch philosopher Benedict de Spinoza and the British scientist Robert Boyle, with a view to explicating what the twentieth-century French philosopher Gilles Deleuze considers to be the difference between science and philosophy. The two main themes that are usually drawn from the correspondence of Boyle and Spinoza, and used to polarize the exchange, are the different views on scientific methodology and on the nature of matter that are attributed to each correspondent. Commentators have tended to focus on one or the other of these themes in order to champion either Boyle or Spinoza in their assessment of the exchange. This paper draws upon the resources made available by Gilles Deleuze and Felix Guattari in their major work What is Philosophy?, in order to offer a more balanced account of the exchange, which in its turn contributes to our understanding of Deleuze and Guattari's conception of the difference between science and philosophy.
\end{abstract}

Keywords: Spinoza, Boyle, Deleuze, scientific methodology, rationalism, experimentalism, plane of immanence, plane of reference

A number of studies have been devoted to the examination of the correspondence that took place between Benedict de Spinoza (1632-77) and Robert Boyle (1627-91), by means of the intermediary Henry Oldenburg, during the period from 1661 to 1663 . It was upon the instigation of Oldenburg that Spinoza was made aware of Boyle's then recently published book Certain Physiological Essays (1661). ${ }^{1}$ Boyle was a founding member of the Royal Society (established in 1644), and is considered to be one of the leading English natural philosophers of the Scientific Revolution. He was the first to style his type of natural philosophy as the corpuscular philosophy, which brought together the role of particulate matter in the explanation of natural phenomena with the dual mechanical principles of matter and motion. Oldenburg, the then secretary to the Royal 


\section{Paragraph}

Society, had met Spinoza during a trip to Holland in the summer of 1661. The correspondence contains Spinoza's responses to a number of experiments on nitre, and on solidity and fluidity, that Boyle gives details of in the Essays.

The two main themes that are usually drawn from the correspondence and used to polarize the exchange are the different views on scientific methodology and the nature of matter that are attributed to each correspondent. Commentators have tended to focus on one or the other of these themes in order to champion either Boyle or Spinoza in their assessment of the exchange. This paper draws upon the resources made available by Gilles Deleuze and Felix Guattari in their major work What is Philosophy?, ${ }^{2}$ in particular their distinction between science and philosophy, to offer a more balanced account of the exchange. Those commentators who champion Boyle invariably offer a scientific assessment of the exchange that relies upon a general presentation of the limitations of rationalist philosophy, and by extension Spinoza's philosophy, to provide the grounds for the development of an adequate scientific methodology. ${ }^{3}$ Whereas those who want to balance the ledger by offering a philosophical defence of Spinoza make a lot of the inconsistencies in Boyle's natural philosophy in comparison to Spinoza's metaphysics. ${ }^{4}$

Neither of these approaches is up to the task of providing an adequate assessment of the exchange. On the one hand, as Peter Anstey notes, 'Boyle was adamant' that his mechanical philosophy 'was a theory and not a set of metaphysical first principles upon which a science of nature was to be based'. 5 To find Boyle inconsistent in this respect is to misconstrue the nature of his project. Indeed, Boyle had a 'self-confessed aversion to system building' and was not interested in systematizing the corpuscular philosophy. ${ }^{6}$ On the other hand, those who champion Boyle contrast the importance of Boyle's experiments to the development of a properly empirical scientific knowledge with the metaphysical principles of Spinoza's mechanical physics. From this point of view, it is tempting to regard the correspondence between Spinoza and Boyle as providing a particular case of the opposition between a quintessential rationalism and an emergent experimentalism. The concept of rationalism in this instance being characterized as the exclusive doctrine that knowledge is deduced from principles that are determined independently of experience, or at least such that they have a priority over it. And experimentalism being characterized conversely as an empirical doctrine that advocates the use of experimental methods in determining the validity of ideas, 
the principles of which are hypotheses. According to such a reading, Spinoza is criticized as being the pure philosopher who refuses to admit hypotheses that put rational principles into self-contradiction, and Boyle is championed as the pre-positivist scientist who refuses to reason beyond the facts and relations that are determined by experimentation. This sets up a radical antagonism between two mutually exclusive positions, both in terms of the particular theses that they each develop, and in terms of the theoretical conception that they each have of their own work. ${ }^{7}$ Elkhanan Yakira can be thanked for judiciously pointing out that such an interpretation is "both simplistic and excessively limited'. ${ }^{8}$ The distinction between them is only problematically schematized as that between a quintessential rationalist and an experimentalist championing the new science. If the exchange that took place between Boyle and Spinoza is examined with the due attention that it deserves, it should become clear that the points of disagreement in the correspondence are of much less importance than a superficial reading of the correspondence would at first suggest. ${ }^{9}$

The characterization of Spinoza as a typical rationalist philosopher risks obscuring Spinoza's own engagement with, and development of, the new mechanistic science, particularly when it comes to the very empirical and constitutive nature of Spinoza's first kind of knowledge, or the imagination, and its importance for the development of reason, or the second kind of knowledge. Just as it is problematic to presume that Boyle's speculations about the textures of particles, ${ }^{10}$ which are of singular importance to the kinds of interpretations that he gives of his experiments, are vindicated by subsequent developments in chemistry. Indeed, there are certain moments in the correspondence that could have given Spinoza concern for the adequacy with which Boyle was able to distinguish the trajectory of his scientific endeavours from the Scholastic tradition that both of them were keen to move beyond. Rather than attempting to assess the distinction between the two correspondents as being characteristic of the distinction between two different kinds of philosophy - that is, between Spinoza's particular brand of rationalism and the kind of empirical natural philosophy that Boyle's experimentalism implies - or between the two different scientific methodologies that can be extracted respectively from these positions, I propose to assess the distinction from the point of view of the question, already implicitly problematized, of the relation between science and philosophy.

Boyle and Spinoza were corresponding at the dawn of a new scientific era, and Boyle can be characterized 'as a transitional figure 


\section{Paragraph}

in the parting of ways for philosophy and science'. ${ }^{11}$ The limited and episodic nature of the exchange provides the focus for an examination of this relation precisely at the time when science and philosophy began to distinguish themselves as separate disciplines. The account of the difference between science and philosophy that is given by Deleuze and Guattari in What is Philosophy? offers new resources to examine the controversial exchange between Spinoza and Boyle, and this exchange in turn provides the resources for an explication of Deleuze and Guattari's understanding of the difference between science and philosophy.

In What is Philosophy?, Deleuze and Guattari define philosophy as 'the creation of concepts' (WIP, 41) which enter into resonance with one another on what they define as 'a plane of immanence' (35). Philosophy is therefore 'at once concept creation and instituting of the plane' (41), that is, philosophy both creates concepts and generates the plane on which they are then distributed. Unlike philosophy, the object of science, for Deleuze and Guattari, is not concepts but rather functions that are presented as propositions in discursive systems' (117). Like concepts, functions also need to be created, and once created, they are distributed not on planes of immanence, but rather on planes of reference.

For Deleuze and Guattari, the concept has nothing to do with representations nor with propositions: it is not simply the idea of a form, or a container for cognitive content, nor is it simply a bearer of truth-values. Instead, they argue, 'All concepts are connected to problems without which they would have no meaning and which themselves can only be isolated or understood as their solution emerges' (16). A concept therefore only has meaning as a function of the problem 'that it resolves or helps to resolve' (79). The meaning that the problem confers on the concept is not the immediate signification of a proposition. The problem should not be reduced to the case of a solution which immediately exhausts the instance of the problem, nor should it be confused with the ordinary process of putting 'the same subject of a thesis into contradiction'. ${ }^{12}$ Rather than determining the problem by the assurance of a solution, the problem should be understood to be determined by the urgency of its related questions. Therefore, rather than moving from problems to solutions, Deleuze and Guattari propose moving from the problem to what conditions the problem 'and forms the cases that resolve it'. ${ }^{13}$ Problems can therefore be understood to generate new modes of questioning, opening different perspectives on the more familiar or conferring 
interest on the given that until then had remained insignificant. ${ }^{14}$ The components of a concept are those other problematic or fragmentary concepts that have been created in the past that are reoriented in relation to one another by virtue of a particular problem. The concept as such is a point of condensation, or neighbourhood, which governs and gives consistency to these heterogenous components. ${ }^{15}$ Deleuze and Guattari describe concepts as 'centers of vibrations, each in itself and every one in relation to all the others. This is why they all resonate rather than cohere or correspond with each other' (WIP, 23). The concept is a point or 'state of absolute survey (survol) in relation to its components', which are 'traversed by it at infinite speed' (21). In this way, the concept is 'immediately co-present to all its components' (20). The infinite speed with which the concept traverses all of its components in a state of absolute survey is retained from the virtual, which is characterized by Deleuze and Guattari in What is Philosophy? as 'chaos'. This is not the chaos of chaos theory, as Deleuze and Guattari argue:

Chaos is defined not so much by its disorder as by the infinite speed with which every form taking shape in it vanishes. It is a void that is not a nothingness but a virtual, containing all possible particles and drawing out all possible forms, which spring up only to disappear immediately, without consistency or reference, without consequence. (118)

The example that Deleuze and Guattari draw upon for their characterization of chaos is the crystallization of a superfused liquid. ${ }^{16}$ It is in the very relation of resonance, co-presence, or absolute survey that the infinite speed with which forms take shape and vanish in chaos is retained in philosophy, and that the virtual (chaos) is given consistency. It is this very consistency that constitutes the plane of immanence of a particular concept, and that determines a particular 'image of thought' in relation to that concept. As Deleuze and Guattari note: 'The Plane of immanence is not a concept that is or can be thought but rather the image of thought, the image thought gives itself of what it means to think, to make use of thought, to find one's bearings in thought' (37).

Deleuze and Guattari argue that 'every great philosopher lay[s] out a new plane of immanence' (51), such that 'there are varied and distinct planes of immanence that (...) succeed and contest each other in history' (39). Indeed they argue that the history of philosophy 'exhibits so many quite distinct planes' that 'we can and must presuppose a multiplicity of planes' (50). The actual practice 


\section{Paragraph}

of philosophy, according to Deleuze and Guattari, consists above all in disengaging problematic or fragmentary concepts that have been created by philosophers of the past - along with the plane of immanence that each concept generated and on which it is distributed - from the supposed order of succession of achieved philosophical systems, by grafting these concepts (of the past) onto one another to create new concepts. This is done by selecting those concepts (of the past) which enter into reciprocal relation or are problematized with the signature concepts of other philosophers, ${ }^{17}$ thereby extending each of the associated planes of immanence by determining their actual coexistence in relation to one another.

Deleuze and Guattari do not consider the history of philosophy to be a succession of achieved philosophical systems. Instead they characterize a time of philosophy that is rather 'a grandiose time of coexistence that does not exclude the before and after but superimposes them in a stratigraphic order' (59). The 'time of philosophy' is therefore not the subject of a future (after) and a past (before) - Scotus before Descartes, Spinoza after Descartes - but rather constitutes a "stratigraphic time where "before" and "after" indicate only an order of superpositions' (58). Duns Scotus can therefore come 'after' Descartes, insofar as the Scotist plane of immanence, on which the concept of the univocity of being is distributed, is superimposed on the Cartesian plane of immanence, on which the concept of substance dualism is distributed. ${ }^{18}$ These concepts are selected and grafted together by Spinoza to create his concept of substance monism. Deleuze and Guattari maintain that 'very old strata can rise to the surface again, can cut a path through the formations that covered them and surface directly on the current stratum to which they impart new curvature' (58). Philosophical concepts therefore do not enter into the linear progression of an evolutionary history, but are rather distributed over a plane of immanence that generates instead an intensive temporality of its own. It is the process of the selection of problematic or fragmentary concepts (of the past) that determines the creation of new concepts and it is the operation of this process that Deleuze and Guattari consider to be characteristic of the practice of philosophy.

Problems subtend not only the creation of concepts, but also the creation of functions. However, while concepts conserve the infinite speed of the virtual (chaos), a function effects a 'fantastic slowing down' (118). 'To slow down is to set a limit in chaos', to limit the speed with which forms take shape and vanish in chaos. Deleuze and Guattari argue that 'it is by slowing down that matter, as well 
as the scientific thought able to penetrate it with propositions, is actualized' (118). What science does in response to problems is to substitute a horizon for the infinite, in order to determine solutions. It does this by giving reference points to the virtual (chaos), reference points such as the universal constants of physics: the invariance of the speed of light, Plank's constant, absolute zero, etc. And it is with these reference points, or 'limits', that science constructs functions. '[Science] relinquishes the infinite, infinite speed, in order to gain $a$ reference able to actualize the virtual' (118). Science actualizes the virtual (chaos) through functions. A function is composed of elements, what Deleuze and Guattari call 'functives', which include these limits and the variables that they are determined in relation to. A function therefore consists of a functive regarded in its relation to one or more other functives in terms of which it may be expressed. This relationality determines a state of affairs that actualizes the virtual on a plane of reference and in a system of co-ordinates. As they note: 'reference is a relationship (...) of the variable with the limit' $(118-19)$. The plane of reference of science is a discursive system in which functions are presented as propositions determinative of states of affairs. The plane of reference is not unitary, but is instead constituted by the irreducible, heterogenous systems of co-ordinates that each limit generates on its own account (119-20). The meaning that a problem confers on a function is the state of affairs in which it insists.

Deleuze and Guattari also reconceptualize the history of science, characterizing instead a time of science that is not confined to a linear temporal succession any more than philosophy is' (124). But, instead of a stratigraphic time, which expresses before and after in an order of superimpositions, they maintain that 'science displays a peculiarly serial, ramified time, in which the before (the previous) always designates bifurcations and ruptures to come, and the after designates retroactive reconnections' (124). One of the results of this is a different way of conceptualizing scientific progress. Scientists' proper names, when understood according to this other time, mark 'points of rupture and points of reconnection' (125) in the ramified time of scientific development.

The correspondence between Spinoza and Boyle can be construed as being played out across these two quite different planes: the plane of immanence of philosophy; and the plane of reference of science. On the one hand, there is an interrogation of the emerging domain of corpuscular chemistry that turns around the problem of 


\section{Paragraph}

the nature and composition of nitre, an interrogation that is properly speaking philosophical for Spinoza, but that remains scientific for Boyle. On the other hand, there is a specific interrogation between the two protagonists, at the level of scientific methodology, of the adequacy of the particular experiments being carried out to this end. The difference between the different positions taken up by each of the protagonists in their correspondence, as we shall see, gives an exemplary expression of the difference between the plane of reference of Boyle's corpuscular chemistry and the plane of immanence of Spinoza's metaphysics.

Mechanics was the emerging scientific discipline of the time that became the general principle of scientific explication and practice, what Deleuze and Guattari would describe as one of the planes of reference for the emerging scientific enterprise. Spinoza, as much as Boyle, adopts the mechanical principles as a method of explication. While Spinoza incorporates them into his philosophy alongside the principles of his metaphysics, the mechanical principles that Boyle uses to support a corpuscular world view are determined by hypotheses, and the ultimate criteria of the veracity of hypotheses is experimental evidence. Even though such a mechanics promised to provide a comprehensive heuristic structure for the explanation of all corporeal phenomena, Boyle was committed to a number of speculations about corpuscular entities that at the time remained beyond its explanatory resources. ${ }^{19}$ These included the strong 'empirical sense that some substances were in a chemically significant way permanently distinct from other substances', for example the end products of chemical analysis, for which Boyle's experiments on nitre will function as an example. The theoretically equivalent speculation being 'that some mechanical textures of particles possessed a characteristic quality of being indisruptable (sic)'. ${ }^{20}$ It was only much later, with the development of analytic chemistry towards the end of the eighteenth century, that such speculations were adequately reformulated with the postulation of entities and qualities that were unfamiliar to Boyle, and whose existence was then able to be demonstrated experimentally. Macherey quite correctly warns against being tempted to loan to Boyle the conceptions of analytic chemistry that are radically different to those of his corpuscular chemistry. ${ }^{21}$ Indeed, Boyle's 'theory of matter is now completely debunked'. ${ }^{22}$

The distinction between different particles of matter that Boyle introduces looked forward to the notion of a chemical element, which only really appeared much later with Lavoisier (1743-94). In 
the context of Boyle's corpuscular chemistry, such an element would be understood simply as an elementary body, or particle, composed of the particulate matter that was the ultimate material constituent of all corporeal objects. ${ }^{23}$ This distinction could be understood to identify in nascent form the notion of a particle of matter having irreducible chemical properties which are not lost when it is integrated with another to create a compound matter. However, Boyle's speculations about the non-disruptable quality of some textures of particles and Lavoisier's notion of the chemical element are quite different. Lavoisier clarified the concept of a chemical element as a simple substance, rather than a corpuscular object, that could not be broken down by any known method of chemical analysis, and he devised a theory of the formation of chemical compounds from elements. He also compiled a list of elements, which included oxygen, nitrogen, hydrogen, phosphorus, mercury, zinc, and sulphur, that formed the basis for the modern periodic table of chemical elements, developed by Mendeleev in 1869. So not only did they not have a conception of a chemical element, but also neither Spinoza nor Boyle could have had a conception of chemical reaction in the sense that it takes after Lavoisier.

The speculations of Boyle's corpuscular chemistry designate the bifurcations and ruptures to come in the emerging discipline of chemistry that subsequently led to the development of the plane of reference that is characteristic of analytic chemistry. It is important to note however that it is only retroactively that this plane of reference is reconnected with Boyle's speculations. To read the relation between the two as having been linearly, or serially, determined, that is, as if Boyle's speculations lead directly to the development of the notion of chemical element, would be to overdetermine Boyle's contribution to the development of analytic chemistry, and to succumb to the temptation that Macherey warns against. According to the ramified time of science, the connection between Boyle's speculations and the developments in analytic chemistry are rather made retrospectively, from the latter to the former.

According to the principles of mechanics that both Boyle and Spinoza adopt and develop, the composition of different bodies, in terms of shape and movement, or material textures, is determined mechanically by the arrangement of their constituent particles, themselves without quality, however these arrangements are manifested to the senses in the form of qualities. Boyle's speculations do seem to imply an intrinsic nature proper to particles that differs from one 


\section{Paragraph}

particle to another, the implication being that matter has qualities that are not solely reducible to the movement of particles. This would contradict Spinoza's mechanism of the second part of the Ethics where he states that 'Bodies are distinguished from one another by reason of motion and rest, speed and slowness, and not by reason of substance'. ${ }^{24}$ However, Boyle doesn't actually give a clear indication of his view of the nature of matter until after the correspondence, ${ }^{25}$ and even then his position remains inconsistent. So, while not furnishing us with a definitive view as to the ontological status of the sensible qualities, Boyle recontextualizes the discussion of many of the central issues that pertain to the nature of the sensible qualities within the development of his corpuscular chemistry. ${ }^{26}$ The question, however remains: Do Boyle's speculations make a strong enough claim to the stability of an intrinsic nature proper to different particles to cause Spinoza concern?

In his first letter to Boyle, Spinoza argues that it is not necessary to examine whether the demonstrations that Boyle offers to show that 'the tangible [or sensible] qualities depend only on motion, shape, and the remaining mechanical affections' are 'completely convincing' because 'he does not present these demonstrations as Mathematical' (Letter VI). Whatever speculative content there is to Boyle's understanding of the nature of the sensible qualities, this comment indicates that Spinoza is not overly concerned by it, because he does not consider Boyle to have demonstrated this with any rigour, which is what Spinoza's reference to mathematics serves to indicate. So contrary to the above suggestion that this speculation on Boyle's part would contradict Spinoza's mechanism, Boyle's speculation about the stability of these qualities, or the non-disruptability of certain characteristic qualities at a chemical level, does not necessarily imply a difference in intrinsic nature between the particles exhibiting such qualitative stability. In fact, Spinoza's distinction between fluid, soft and hard bodies in the Lemmas of the second part of the Ethics would have provided support for such speculation. ${ }^{27}$

It is the very transitional nature of the corpuscular chemistry which Boyle was in the process of developing that leaves his comments in the correspondence open to criticism of this sort. As it turns out, the speculative component of Boyle's train of thought proved justifiable, despite being based on a theory of matter that was proved incorrect. This could, however, only be determined retrospectively, from the point of view of the subsequent developments in analytic chemistry. Indeed, Antonio Clericuzio argues that the correspondence 'shows that Boyle's preoccupations in his relations with the 
mechanical philosophers was to safeguard the role of chemistry as a discipline independent from physics' ${ }^{28}$ It is therefore rather to this end that Boyle's speculations about the chemical properties of particles should be understood to have been directed. Boyle's corpuscular chemistry can therefore be understood as one of the early bifurcations that occurs in the transitional stage of the differentiation of science from philosophy, and also of chemistry from physics, which is only retroactively reconnected with the plane of reference characteristic of analytic chemistry, marked by the proper names of Lavoisier and Mendeleev.

One of the differences between science and philosophy that Deleuze and Guattari consider to be 'impossible to overcome' is that 'proper names mark in one case a juxtaposition of reference and in the other a superimposition of layer' (WIP, 128). In science proper names play the role of 'partial observers' that are 'installed like a golem in the system of reference' of 'the things studied' (130), that is, as 'points of view in things themselves' (132). For example, the Boyle of Boyle's Law, which states the inverse proportionality of pressure and volume at a given temperature, is also the Boyle who is retroactively understood to have installed himself by means of his very speculations as a partial observer at the level of the interacting corpuscules in his own experiments on nitre. Whereas for philosophy, proper names play the role of 'conceptual personae' which differentiate the planes of immanence of different fragmentary concepts that are superimposed on one another in the process of the construction of concepts (Scotus after - because superimposed upon - Descartes). In addition to Boyle's Law, the proper name Boyle would therefore also designate the bifurcations and ruptures of corpuscular chemistry from physics and the mechanical science of the time; and Lavoisier would designate the bifurcations and ruptures of analytic chemistry that are only retroactively reconnected with Boyle's corpuscular chemistry. It is only by virtue of this relation of bifurcation/rupture and retroactive reconnection that the proper names of Boyle and Lavoisier should be understood to be juxtaposed in relation to one another in the ramified time of science.

A closer examination of the correspondence between Boyle and Spinoza is required in order to support the assessment of the distinction between their replies to one another as being characteristic of the distinction between science and philosophy. In Letter VI, Spinoza responds to Oldenburg giving his 'judgment of what [Boyle] has written (...), noting certain things which seem to [him] obscure, or 


\section{Paragraph}

inadequately demonstrated'. He begins by offering a clear and concise account of Boyle's experiment on nitre, thereby demonstrating that he understood the point of Boyle's interpretation. He writes that Boyle 'infers from his experiment concerning the reconstitution of Nitre that Nitre is something heterogeneous, consisting of fixed and volatile parts, whose nature (so far as the Phenomena are concerned, at least) is nonetheless very different from the nature of the parts of which it is composed, though it arises solely from the mixture of these parts' (Letter VI).

Boyle considered his experiments on nitre to illustrate that the entire body of nitre could be analysed, or decomposed into its constituent parts - fixed nitre and spirit of nitre - that were different or heterogenous, and that the initial nitre could then be reconstituted by 'redintegration' from these different parts. Boyle inferred that the corpuscules of the constituent parts persist unchanged throughout the reactions, and that the reactions were explicable on the basis of his corpuscular chemistry. ${ }^{29}$ The essential point is the process of analysissynthesis that highlights the reversibility of the transformation that nitre is subject to. The modern chemical equations for the reaction, which were only determinable in relation to the plane of reference of science post Lavoisier/Mendeleev but which will serve to assist in assessing both Spinoza's and Boyle's experiments, are as follows:

$$
\begin{aligned}
& 4 \mathrm{KNO}_{3}+3 \mathrm{C} \rightarrow \mathrm{CO}_{2}+2 \mathrm{NO}_{2}+\mathrm{N}_{2}+2 \mathrm{~K}_{2} \mathrm{CO}_{3} \\
& \mathrm{NO}_{2}+\mathrm{H}_{2} \mathrm{O} \rightarrow 2 \mathrm{HNO}_{3} \\
& \mathrm{~K}_{2} \mathrm{CO}_{3}+2 \mathrm{HNO}_{3} \rightarrow 2 \mathrm{KNO}_{3}+\mathrm{H}_{2} \mathrm{O}+\mathrm{CO}_{2}{ }^{30}
\end{aligned}
$$

Boyle put hot coal (C: carbon) into the 'nitre' $\left(\mathrm{KNO}_{3}\right.$ : saltpetre or potassium nitrate), which was decomposed, leaving 'fixed nitre' $\left(\mathrm{K}_{2} \mathrm{CO}_{3}\right.$ : potash or potassium carbonate). The nitrogen dioxide $\left(\mathrm{NO}_{2}\right)$ gas, which when condensed on glass as vapour, or mixed with water $\left(\mathrm{H}_{2} \mathrm{O}\right)$, produces spirit of nitre $\left(\mathrm{HNO}_{3}\right.$ : acqua fortis or nitric acid), was left to escape into the open air. Boyle then added spirit of nitre, that was sourced separately, to the fixed nitre until crystals of nitre were formed. The role of carbon in the experiment was unsuspected by Boyle, as was the fact that it combined with certain elements to compose the nitre, and to form carbon dioxide $\left(\mathrm{CO}_{2}\right)$ that was released into the air. 31

In response to Boyle's experiment on nitre, Spinoza argues that in order 'for this conclusion to be regarded as valid', Boyle should have done a further experiment that would have shown that: 'Spirit of Nitre 
is not really Nitre and cannot be solidified or crystallized without the aid of the alkaline salt' (Letter VI). Without such an experiment, Spinoza considers the hypothesis of the homogeneity of nitre and its spirit, which he will introduce as an alternative explanation of the experiment, not to have been ruled out.

Spinoza also claims that "what the Distinguished Author says he observed with the aid of the scale (\$9)', does 'nothing to confirm his conclusion' (Letter VI). In $\$ 9$ of the Essays, Boyle reports that he weighed the spirit of nitre necessary to fully dissolve the fixed nitre and compared this with the weight lost by the nitre when it was separated from its spirit, and found that 'the weights were nearly, but not quite equal'. ${ }^{32}$ Spinoza maintains that Boyle's quantitative check did not support his case. He argues that Boyle should have at least tried to show that, in the decomposition of nitre, a given quantity of nitre always produces that same quantity of fixed nitre or that the quantity of fixed salt obtained was always proportional to the amount of nitre required to produce it. While Spinoza's reasoning is quite justified in this criticism, it should be noted that he too fails to satisfy these requirements in his own experiment, thought he does acknowledge that he does not have the means to do so. Despite this, he incorrectly claims that, if this quantitative check 'could be made accurately, it would completely confirm what I wished to infer' (Letter VI), that is, the homogeneity of nitre and its spirit.

Spinoza considers this to be 'the simplest explanation of $(. .$.$) the$ reconstitution of Nitre'. His alternative explanation of the experiments is that the differences observed between nitre and its spirit are due to the different states of motion and rest of the particles: 'the particles of the Nitre are at rest, whereas those of the spirit of Nitre, having been considerably stirred up, keep one another in motion' (Letter VI). The distinct properties of the nitre and of its spirit, which Boyle had used to support the inference that they were heterogenous particles endowed with different natures, are here explained by Spinoza in purely mechanical terms. For Spinoza it is primarily and principally according to differences in movement and rest that material and physical differences must be explained. It is this principle that Spinoza uses to explain not only the observed differences between nitre and its spirit, but also the differences in their taste and inflammability.

As for the fixed salt, Spinoza considers it to be an impurity in the nitre and to do 'nothing to constitute the essence of Nitre' (Letter VI), the analysis of which he considered to be a process of purification. The nitre becomes brittle upon heating, which allows the separation 


\section{Paragraph}

of the particles of nitre that are in motion from its impurities which remain at rest as the fixed nitre. Spinoza is correct to recognize that the fixed nitre contains impurities, however, he too fails to correlate this with the carbon introduced into the process by the coal. Any quantitative check of the process that did not take into account the role of carbon was bound to fail. Both Spinoza and Boyle err in this respect.

Spinoza's mechanical account of the reconstitution of nitre is as follows: 'with the aid of water or air, the fixed salt is loosened and made more flexible, then it is sufficiently able to restrain the impetus of the particles of [A: spirit of] Nitre and to force them to lose the motion they had, and come to rest again (just as a cannonball loses its motion when it hits sand or mud)' (Letter VI).

In response, Oldenburg writes that Boyle 'thinks what you suppose about how it occurs - that you consider the fixed salt of Nitre to be its impurities, and other such things - is said gratuitously and without proof (Letter XI). Taking up a position with regards to Spinoza's conjectures, Boyle is reported as claiming that spirit of nitre is nitre 'materially', but not 'formally'. Oldenburg presents Boyle's argument as follows: 'materially, indeed, Spirit of Nitre is Nitre, but not formally, since they differ very greatly in their qualities and powers, viz. in taste, smell, volatility, power of dissolving metals, of changing the colors of vegetables, etc.' (Letter XI). Spirit of nitre is 'materially' nitre, since it is a constituent part of it, but it isn't 'formally' nitre, since its nature, as manifested by its properties, is different. For Boyle, fixed nitre is therefore also equally found as such in nitre. But by using this Aristotelian terminology to affirm that nitre and its spirit are formally distinct, Boyle risks problematizing the very distinction that he is trying to establish between his own corpuscular chemistry and the Scholastic doctrine of substantial forms. According to this doctrine, the properties of a natural substance like nitre were determined by its possession of a 'form', which would be destroyed if the substance underwent substantial change such as that brought about in the experiment. The redintegration of nitre was intended to show that such substances could be broken up into more elementary constituents and then made whole again by reuniting the constituents, which persisted unchanged throughout the reactions. So the properties of the whole were to be explained, not by its possession of a form, but by the composition of its parts. ${ }^{33}$

Peter Anstey argues that the use of such anachronistic terminology 'was part of natural philosophy parlance'. So while Boyle explicitly 
rejects the Scholastic doctrine of substantial forms, 'he is quite prepared to categorize the qualities in Aristotelian terms'. It is also important to note that by Boyle's day the Aristotelian qualities had become 'the explananda and not the explanans', that is, there was an 'inversion of the explanatory role of the Aristotelian' qualities. ${ }^{34}$ So, despite referring to the distinction between nitre and its parts using Aristotelian terms, the actual distinction still required explication, and what Boyle was in fact suggesting is that his corpuscular explanation displaces the Scholastic doctrine in this respect.

In response to Oldenburg's disclaimer that Boyle's 'purpose was not so much to show that this is a truly Philosophic and perfect Analysis of Nitre, as to explain that the common doctrine of Substantial Forms and Qualities, received in the Schools, rests on a weak foundation' (Letter XI), Spinoza writes that 'I did not think, indeed I could not have persuaded myself, that this Most Learned Gentleman had no other object in his Treatise on Nitre than to show the weak foundations of that childish and frivolous doctrine of Substantial Forms and Qualities' (Letter XIII). Spinoza considered this to have 'already been more than adequately demonstrated by Bacon and later by Descartes' (Letter VI). Spinoza is obviously not persuaded that Boyle only proposed to show that the doctrine of substantial forms and qualities has no solid foundation. This opinion is vindicated by Oldenburg's comments that Boyle's aim was 'primarily to show the usefulness of Chemistry for confirming the Mechanical principles of Philosophy, and that he had not found these matters treated so clearly by others' (Letter XI). Nevertheless, this does not detract from the earlier claim that Boyle's aim does seem to have been concerned to displace the Scholastic doctrine of substantial forms. It just affirms that this was not conducted at the level of conceptualization, but rather at the level of experimental demonstration, that is, not philosophically but rather scientifically. So, in Oldenburg's words, Boyle 'has shown that the thing [Analysis of Nitre] occurs thus, but has not discussed how it occurs, which seems to be the subject of your [Spinoza's] conjecture. Nor has he determined anything about it, since that was beyond his purpose' (Letter XI).

In the final letter of the exchange, Oldenburg writes that Boyle 'had only wished to show that the various textures of bodies produce their various differences, that from these proceed quite different effects, and that so long as the resolution to prime matter has not been 


\section{Paragraph}

accomplished, Philosophers and others rightly infer some heterogeneity from this' (Letter XVI). As far as Oldenburg is concerned, he doesn't 'think that there is any fundamental difference between [Spinoza] and Mr. Boyle here' (Letter XVI). Ostensibly, Oldenburg is right: it is possible to distinguish between, on the one hand, ideal corporeal elements, particles or 'the simplest bodies', ${ }^{35}$ which are pure rational constructions that are not apprehended in experience, elements whose simplicity renders them in a certain way homogenous with one another; and, on the other hand, real bodies, or modes, as presented in experience with all the differences in complexity of their composition, which could well be interpreted in terms of heterogeneity, on the condition of understanding this heterogeneity to be relative and not absolute. It would be accurate to claim that Boyle did not actually envisage attributing an absolutely heterogenous nature to nitre itself, but wanted only to induce a certain heterogeneity of the complexity of its composition such as was revealed by the experiments that he conducted. ${ }^{36}$

Boyle accounted for the redintegration on the grounds of his speculations about the chemical properties of the corpuscules, and did not make any attempt to deduce them from the mechanical principles, as Spinoza did. ${ }^{37}$ Of course, Spinoza's conclusions concerning the redintegration of nitre were false, and as for Boyle, the chemical reaction that nitre undergoes is much more complex than simple decomposition. On the question of determining that all variations of bodies happen according to the laws of mechanics, Spinoza does not think that Boyle's experiments furnish us with a proof more clarifying than other 'readily available experiments' (Letter XIII). This claim is made from the point of view of the supposition of the homogeneity of nitre and its spirit, which requires only a simple mechanical explanation that adds nothing to the already understood principle.

In response, Boyle is presented as claiming 'that there is a great difference between readily available experiments (where we do not know what Nature contributes and what things intervene) and experiments where it is definitely known what things are brought in' (Letter XI). Of course, we have already seen that Boyle commits a number of errors in his judgement about 'what things are brought in' to the experiments. However, despite erroneously supposing fixed nitre to be simply a part of nitre, and therefore not grasping 'the contribution made to his experiment by the coal he used to kindle the nitre', the very distinction that Boyle's speculations posed 'shows the 
sophistication about experiments that made him a great scientist' ${ }^{38}$ In fact, it is less these particular experiments involving nitre, and more the way in which Boyle systematized, not the corpuscular philosophy, but the practical method for ensuring that the observational and recording process involved in scientific experimentation accumulated into a body of knowledge which was widely disseminated through publication, was accessible to the public, via public demonstrations, and was self-correcting, by means of the requirement to replicate and review the experiments implied in this process. It is this process that marks the parting of ways for science and philosophy, and which constitutes Boyle's lasting contribution to the development of the plane of reference of science. It is this process that is more generally designated by the proper name 'Boyle'.

A number of commentators are also critical of these comments by Spinoza and of what they consider to be Spinoza's understanding of experiments, that is, that he relegates them to the imagination because they deal with the senses, and that he therefore considers them to have no bearing on the principles of reason. This understanding belies the constitutive nature of the imagination in Spinoza's epistemology, which he characterizes as the first kind of knowledge, and its role in the development of reason, or the second kind of knowledge. When, in Letter VI, Spinoza states that fluidity and solidity belong to the class of notions determined by the use of the senses and therefore belong to the imagination, this is not to relegate these notions to some ineffective epistemological category that remains opaque to the understanding, but rather characterizes the kind of understanding that is able to be determined by the senses as being only partial: a partial or limited knowledge. The challenge is to attempt to improve that understanding of these states. The process itself is far from different to that proposed by Boyle's process of experimentation, where a body of knowledge, or plane of reference, is developed in relation to a series of experiments. For Spinoza, a sense of the fluidity of something represents only a partial understanding of the nature of fluidity. The rational component of an understanding of 'the nature of a fluid in general' would be 'to know that we can move our hand [A: in it] in all directions without any resistance, with a motion proportionate to the fluid' (Letter VI), that is, to know that it is the particular state of motion of the particles of the fluid that determines them as a fluid, a knowledge supported by the experiment with your hand. 'This is evident enough to those who attend sufficiently to those Notions which explain Nature as it is in itself, not as it is related to human sense 


\section{Paragraph}

perception. Not that on that account I scorn this history as useless. On the contrary, if this were done concerning each fluid, as accurately and reliably as possible, I would judge it very useful for understanding their special differences. This is something all Philosophers ought greatly to desire, as being very necessary' (Letter VI). The rational idea of a particular fluid, or of the fluidity of the fluid (or solidity of the solid, depending on what the case may be) involves both rational and sensible components. The sense of fluidity is not displaced by the rational idea of fluidity, but remains the sensible component of the rational idea of fluidity and allows the fluidity of different fluids to be differentiated. The sensible component of a rational idea would be a false idea only if it were considered to be all that was necessary in order to understand the idea, that is, if it were itself considered to be the rational idea. The imagination for Spinoza is in this way a constitutive component of reason. ${ }^{39}$ Spinoza considers this one observation to indicate 'completely the nature of a fluid' (Letter VI).

Spinoza therefore does not disdain experiments per se; in fact he reproached Boyle in this instance for not having experimented enough. He maintains that Boyle was not consistent enough in his endeavour to give only mechanical explanations of natural phenomena. And it is by placing himself in an experimental point of view, by attempting to replicate the experiments, that Spinoza engages with and is critical of Boyle's experiments. Boyle, as much as Spinoza, is aware of the limited character of the knowledge derived from experiments, even if he does not agree, in the case of these particular experiments, with the placement of this limit. Boyle is concerned to push the boundaries of this limit imposed by mechanics in order to account for his speculations about corpuscular chemistry. He did not want to give just mechanical explanations, but to distinguish properly chemical from physical explanations. Despite the criticisms that each makes of the other's experiments, these criticisms are made from within the same mechanical view of the world. This requires the tacit acceptance by both men of a certain number of general presuppositions associated with the problematic of deploying the mechanical principles in relation to what was in the process of being established as their respective disciplines. All of this occurs prior to the expression of particular points of disagreement in the correspondence.

The difference between Boyle and Spinoza's respective accounts of the experiment can therefore be understood according to the different way that they each respond to the particular problematic about the nature of nitre, that is, whether it is heterogenous or homogenous. 
Spinoza relates this problematic to his philosophy and the distinction between the modes and the substance of which they are the affections, while Boyle relates it to his corpuscular chemistry in an attempt to give ground to his speculations about the function of a particle's chemical properties. The debate between the scientist and the philosopher bears exemplary witness to the emerging distinction between the discipline of science and the discourse of philosophy. The fundamental point, however, is that this division emerges solely because it is between a philosopher and a scientist who are already in agreement on the essentials of the principles of mechanics. Their positions are therefore far from being mutually exclusive, as is suggested by the more scientific assessments of the exchange.

Deleuze and Guattari suggest that science and philosophy take different paths, 'because philosophical concepts have events for consistency whereas scientific functions have states of affairs or mixtures for reference: through concepts, philosophy continually extracts a consistent event from the state of affairs (...) whereas through functions, science continually actualizes the event in a state of affairs (...) that can be referred to' (WIP, 126). What I would like to suggest is that this difference between science and philosophy is characteristic of the difference between the way that Boyle and Spinoza engage with the problem of the redintegration of nitre. The state of affairs to which Deleuze and Guattari refer can be characterized in the example of the Boyle-Spinoza correspondence by the particular experiments that are in question. The event that is actualized would be, from the point of view of science, the hypothesis of the redintegration of nitre. Deleuze and Guattari maintain that responding to such a problem, whether from the point of view of science or philosophy, 'does not consist in answering a question but in (...) co-adapting (...) corresponding elements in the process of being determined' (133). For philosophy, this consists, as we have seen, in co-adapting problematic or fragmentary concepts (of the past); whereas for science this involves choosing 'the good independent variables' - in the present example these would be nitre and its heterogenous parts: spirit of nitre and fixed nitre - installing the effective partial observer on a particular route' - that is, Boyle installing himself at the level of the interacting corpuscules in the redintegration experiment - 'and constructing the best coordinates of an equation or function' (133). Boyle's failure to recognize the role of carbon in the experiments rather limits his efforts in this respect, though the function could be retroactively represented by the chemical equation of the dual reactions presented above. 


\section{Paragraph}

Deleuze and Guattari further distinguish philosophy from science by maintaining that when an object - for example, nitre composed of heterogenous parts - is 'scientifically constructed by functions, its philosophical concept, which is by no means given in the function, must still be discovered' (WIP, 117). Spinoza is interested in trying to determine whether or not a consistent event, and therefore a concept, can be extracted from the state of affairs, characterized by the experiments in question. Deleuze and Guattari maintain that 'The event is actualized or effectuated whenever it is inserted (...) into a state of affairs; but it is counter-effectuated whenever it is abstracted from states of affairs so as to isolate its concept' (159). In support of Oldenburg's disclaimers about Boyle's intentions in the Essays, Boyle is interested in effectuating the event, the redintegration of nitre, by inserting it into a state of affairs, that is, by performing the experiments. Whereas Spinoza is interested in counter-effectuating the event, that is, in abstracting from the experiments, which he also performed, so as to isolate a concept of the event, a concept of the redintegration of nitre and therefore of its nature.

Another distinction that Deleuze and Guattari consider to mark the divergence between philosophy and science and that characterizes the distinction between Boyle and Spinoza as correspondents is that 'philosophical concepts act no more in the constitution of scientific functions than do functions in the constitution of concepts' (WIP, 161). This distinction is further qualified by the claim that it is only 'in their full maturity, and not in the process of their constitution, that concepts and functions necessarily intersect' (161). So, in the case of the exchange between Boyle and Spinoza, because Boyle's corpuscular chemistry was still in the process of development at the time of the correspondence, it could well be argued that his speculations remained as speculations because the scientific functions, the construction of which his speculations contributed to, had not reached their full maturity, and would not do so until the development of the analytic chemistry much later with Lavoisier and Mendeleev. Boyle's interest in effectuating the redintegration of nitre by inserting this hypothesized event into the state of affairs characterized by the experiments in question and Spinoza's attempts to extract a concept of the nature of nitre from them therefore happen at cross purposes. Deleuze and Guattari lament that it is 'unfortunate when scientists do philosophy without really philosophical means or when philosophers do science without real scientific means' (161). Boyle's speculations about the stability, or the non-disruptability of certain characteristic 
qualities at a chemical level were ahead of his time. They designated ruptures to come in the plane of reference of the emerging science of the day, which was unable to support their representation; and the philosophy that he drew upon only risked further obscuring the value of his speculations that later proved to be so decisive - thus Oldenburg disavows any conceptual and therefore philosophical characterization of Boyle's experiments. Spinoza too was limited by the resources of the predominantly Cartesian science of the day, so that the very reversion to its plane of reference when mobilizing an explanation of his experiments only further obscured the value of Boyle's speculations. Deleuze and Guattari maintain that 'philosophy has a fundamental need for the science that is contemporary with it (...), because science constantly intersects with the possibility of concepts' (162). However, this in no way guarantees that a concept will be constructed. Spinoza was unable to counter-effectuate the hypothesized event of redintegration, that is, render the event consistent by extracting a concept from it, and so was unable to isolate a new or different concept of the nature of nitre from the experiments in question.

Rather than succumb to the temptation to loan to Boyle the conceptions of analytic chemistry, and thereby effect a move that lends support to the superficial polarization of the Spinoza-Boyle correspondence as that between a quintessential rationalist and an experimentalist, what I have attempted to demonstrate in this paper is that the rather problematic nature of the exchange provides the focus for an examination of the very divergence that was beginning to emerge between the disciplines of science and philosophy, and indeed encapsulates an example of this very divergence. Despite the fact that their work is similarly grounded on the principles of mechanics, it is the very transitional nature of Boyle's speculations on corpuscular chemistry that provide grounds for distinguishing between the respective projects that they each championed in their correspondence. Boyle's corpuscular chemistry can be understood to be one of the early bifurcations that occurred in the transitional stage of the differentiation of science from philosophy, and of chemistry from physics, which is only able to be retroactively reconnected to the plane of reference characteristic of analytic chemistry. Spinoza took the image of science that Boyle was attempting to construct quite seriously, though in the correspondence he made the mistake of putting forward a simplistic image of it, one that had no scientific value for Boyle. The solutions that Spinoza attempted but was unable to offer to the problem of the redintegration of nitre were philosophical solutions, 


\section{Paragraph}

whereas those that were in nascent form in Boyle's speculations were indeed scientific solutions, and their value to the development of analytic chemistry has been retroactively vindicated.

\section{NOTES}

1 Robert Boyle, Certain Physiological Essays, written at distant times, and on several occasions (London, Herrington, 1661). The book contained 'A physicochymical essay, containing an experiment, with some considerations touching the differing parts and redintegration of salt-petre', and was published in Latin the same year as Tentamina quaedam physiologica, diversis temporibus et occasionibus conscripta (1661). It is the Latin edition that Spinoza would have read.

2 Gilles Deleuze and Félix Guattari, What Is Philosophy?, translated by Graham Burchill and Hugh Tomlinson (London, Verso, 1994). Henceforth WIP.

3 See Henri Daudin, 'Spinoza et la science expérimentale, sa discussion de l'expérience de Boyle', Revue d'Histoire des Sciences 2 (1948), 179-90. See also A.R. Hall and Marie Boas Hall, 'Philosophy and natural philosophy, Boyle and Spinoza', in Mélanges Alexandre Koyré, vol. 2 (Paris, Hermann, 1964).

4 For a defence of Spinoza from the point of view of the inconsistent ontological status of Boyle's elements of matter, see Christopher Lewis, 'Baruch Spinoza. A Critic of Robert Boyle, On Matter', Dialogue. Journal of Phi Sigma Tau 27:1 (1984), 11-22; republished in Spinoza, edited by Genevieve Lloyd, Critical Assessments of Leading Philosophers, vol. 1 (London, Routledge, 2001). For an examination of the exchange from the point of view of their respective religious speculations, see Luisa Simonutti, 'Spinoza and Boyle: Rational Religion and Natural Philosophy', in Religion, Reason and Nature in Early Modern Europe, edited by Robert Crocker (Dordrecht, Kluwer, 2001), (117-38).

5 See Peter Anstey, 'Robert Boyle and the Heuristic Value of Mechanism', Studies in History and Philosophy of Science 33 (2002), 164.

6 Peter Anstey, The Philosophy of Robert Boyle (London, New York, Routledge, 2000), 4.

7 See Pierre Macherey, 'Spinoza lecteur et critique de Boyle', Revue du Nord 77 (1995), 733-74 (744). Macherey's account of the Spinoza-Boyle correspondence is the most balanced to date.

8 Elkhanan Yakira, 'Boyle et Spinoza', Archives de Philosophie 51:1 (1988), 107-24 (109). Although Yakira recognizes the limitations of such a schematic representation of the distinction between Boyle and Spinoza, his response recasts this very distinction in the form of a paradox that can be resolved dialectically in Boyle's favour.

9 See Pierre Macherey, 'Spinoza lecteur et critique de Boyle', 769. 
10 See Peter Anstey, 'Robert Boyle and the Heuristic Value of Mechanism': 'Boyle repeatedly designates texture as a mechanical affection of matter, even though it is not possessed by atomic corpuscles' (164).

11 Peter Anstey, The Philosophy of Robert Boyle, 6.

12 François Zourabichvili, Le Vocabulaire de Deleuze (Paris, Editions Ellipses, 2003), 67.

13 Daniel W. Smith, 'Axiomatics and Problematics as Two Modes of Formalisation: Deleuze's Epistemology of Mathematics', in Virtual Mathematics: the Logic of Difference, edited by Simon Duffy (Manchester, Clinamen Press, 2006), 181.

14 See François Zourabichvili, Le Vocabulaire de Deleuze, 67.

15 For an explication of the terms 'point of condensation' and 'neighbourhood', see Simon Duffy, 'The Mathematics of Deleuze's Differential Logic and Metaphysics,' in Virtual Mathematics, 131, 126-32.

16 This example is presented by Ilya Prigogine and Isabelle Stengers in Entre le temps et l'éternité (Paris, Fayard, 1988), 162-3. See WIP, 225, note 1.

17 Deleuze and Guattari write that: 'The life of philosophers, and what is most external to their work, conforms to the ordinary laws of succession; but their proper names [as conceptual personae] coexist and shine either as luminous points that take us through the components of a concept once more or as the cardinal points of a stratum or layer that continually comes back to us' (WIP, 59).

18 For further discussion of this distinction see Simon Duffy, The Logic of Expression: Quality, Quantity and Intensity in Spinoza, Hegel and Deleuze (Aldershot, Ashgate, 2006), 253-70.

19 Peter Anstey, The Philosophy of Robert Boyle, 4. For further discussion of the heuristic value of mechanical philosophy to Boyle see Anstey, 'Robert Boyle and the Heuristic Value of Mechanism'.

20 See A.R. Hall and Marie Boas Hall, 'Philosophy and natural philosophy, Boyle and Spinoza', 256.

21 Pierre Macherey, 'Spinoza lecteur et critique de Boyle', 762.

22 Peter Anstey, 'Robert Boyle and the Heuristic Value of Mechanism', 173.

23 'Robert Boyle and the Heuristic Value of Mechanism', 164.

24 Ethics, II, P13, L1. All quotes from the Ethics and the correspondence are taken from Benedict de Spinoza, The Collected Works of Spinoza Volume I, edited and translated by Edwin Curley (New Jersey, Princeton University Press, 1985). The Letters are hereafter referred to by their number.

25 Robert Boyle, The Origin of Forms and Qualities according to the Corpuscular Philosophy (London, 1666).

26 See Peter Anstey, The Philosophy of Robert Boyle, 108.

27 See Ethics, II, P13, L3, A3.

28 Antonio Clericuzio, 'A Redefinition of Boyle's Chemistry and Corpuscular Philosophy', Annals of Science 47 (1990), 561-89 (577). 


\section{Paragraph}

29 See Alan Gabbey, 'Spinoza's Natural Science and Methodology', in The Cambridge Companion to Spinoza, edited by Don Garrett (Cambridge/New York, Cambridge University Press, 1996), 178.

30 Henri Daudin incorrectly balances the redintegration (synthesis) equation by mistakenly putting a 2 in front of the carbon dioxide. See 'Spinoza et la science expérimentale', 180.

31 The production of carbon dioxide in similar experiments using coal was discovered by Joseph Black in 1754, who described it as 'fixed air'.

32 Curley, The Collected Works of Spinoza, 174, note 17.

33 The Collected Works of Spinoza, 173, note 15.

34 See Peter Anstey, The Philosophy of Robert Boyle, 22.

35 Ethics, II, P13, L3.

36 See Pierre Macherey, 'Spinoza lecteur et critique de Boyle', 768.

37 Antonio Clericuzio, 'A Redefinition of Boyle's Chemistry and Corpuscular Philosophy', 577.

38 Curley, The Collected Works of Spinoza, 199, note 72.

39 For a discussion of the constitutive role that is played by the imagination in Spinoza's epistemology, see Genevieve Lloyd, Part of Nature: Self-Knowledge in Spinoza's Ethics (Ithaca, NY, Cornell University Press, 1994), 63 ff., and the discussion of 'common notions' in Gilles Deleuze, Spinoza: Practical Philosophy, translated by Robert Hurley (San Francisco, City Lights Books, 1988), 54-8. 